DOI: https://doi.org/10.24867/09BE22Mirkovic

\title{
PRORAČUN OPTIMALNIH TOKOVA SNAGA UZ UVAŽAVANJE PRINCIPA SIGURNOSTI MREŽE
}

\section{SECURITY - CONSTRAINED OPTIMAL POWER FLOW}

\author{
Ivana Mirković, Savo Đukić, Fakultet tehničkih nauka, Novi Sad
}

\section{Oblast - ELEKTROTEHNIKA I RAČUNARSTVO}

Kratak sadržaj - U radu je obrađen problem optimalnih tokova snaga uz uvažavanje sigurnosnih ograničenja mreže (SCOPF). Razmatrani problem je teorijski opisan $i$ matematički formulisan. Metoda i algoritam za rešavanje SCOPF problema su takođe opisani. U praktičnom delu rada algoritam je verifikovan na test sistemu od 34 čvora.

Ključne reči: Optimalni tokovi snaga, Sigurnost sistema, Prenosna mreža

Abstract - The paper discusses the Security Constrained Optimal Power Flow (SCOPF) problem. The problem is theoretically and mathematically desribed. The method and algorithm for solving the SCOPF problem are also described. The algorithm is verified using a 34-bus test system.

Keywords: Optimal power flow, System security, Transmission network

\section{UVOD}

Problem optimalnih tokova snaga (OPF) je razvijan i poboljšavan od 1962. godine kada je prvi put predstavljen u Carpentier-ovoj publikaciji [1]. Carpentier je opisao generalizovani problem ekonomskog dispečinga koji uvažava naponska i druga pogonska ograničenja sistema u formi problema nelinearnog programiranja. Nešto kasnije ovaj problem dobija ime problem optimalnih tokova snaga. Danas se pod OPF problemom podrazumeva bilo koji problem pronalaženja optimalnog stacionarnog stanja elektroenergetskog sistema (EES), a prema nekom kriterijumu. Ovaj proračun obezbeđuju da ne budu narušena sistemska ograničenja uz optimizaciju sistema prema izabranom kriterijumu. U sistemska ograničenja spadaju jednačine mreže, potrošnja, kao i fizička ograničenja proizvodnje aktivne i reaktivne snage, a najpopularnije kriterijumske funkcije u sklopu OPF-a su minimizacije troškova proizvodnje aktivnih snaga generatora, gubitaka aktivne snage $u$ sistemu i odstupanja napona $u$ čvorovima, ali se $u$ praksi sreću i implementacije funkcija za optimizaciju broja upravljačkih akcija, proizvodnje emisionih gasova generatorskih jedinica i rasterećenje dela potrošnje [2].

Željeni režim se uspostavlja manipulacijom upravljačkim veličinama koje mogu da budu izlazna aktivna snaga $i$ naponi u generatorskim čvorovima, podešavanja pozicija teretnih menjača transformatora, podešavanja uglova

\section{NAPOMENA:}

Ovaj rad proistekao je iz master rada čiji mentor je bio doc. dr Savo Đukić. transformatora pomerača faza, signal za uključenje kondenzatora, signal za uključenje reaktora i ostalih raspoloživih resursa u sistemu, pojedinačno ili kombinovano.

SCOPF se koristi za nadzor i analizu sigurnosti sistema. Ima formu OPF problema - optimizuje rad sistema prema odabranom kriterijumu u prisustvu sistemskih ograničenja. Međutim, za razliku od klasičnog proračuna optimalnih tokova snaga [3], koji posmatra samo sistem u datom trenutku i sa datom topologijom, SCOPF mora da „ima uvid“ i u stanje u kojem će se sistem naći nakon promene topologije koja nastaje usled jednostrukog ili višestrukog ispada. Zadatak SCOPF-a je da, pri tome, spreči nastanak narušenih sistemskih ograničenja (ograničenja potrošnje, pogonska ograničenja i sigurnosna ograničenja) u sistemu nakon ispada [4]. Pri tom, uzima se u obzir kriterijumska funkcija mreže u normalnom stanju i sistemska ograničenja mreže u normalnom stanju i u stanju sa ispadom.

Rešenje SCOPF problema ima očekivano lošiju vrednost kriterijumske funkcije u odnosu na stanje koje ponudi klasičan OPF, s obzirom da uvažava dodatna ograničenja koja se odnose i na sistem sa ispadom čime je obezbeđena sigurnost tipa N-1 [5]. Prilikom detekcije svih ispada koji izazivaju narušena ograničenja neophodno je da se vreme potrebno za izvršavanje proračuna, kao i utrošeni resursi za proračun, nalaze u dopustivim granicama.

$\mathrm{S}$ tim u vezi, razvijene su različite metode za detekciju kritičnih ispada. Neke od najčešće primenjivanih metoda su primena direktnog pristupa [6] i primena PTDF faktora [7], gde se za veće sisteme preporučuje korišćenje druge metode jer je direktna simulacija ispada vremenski zahtevan proces.

Primena rešenja SCOPF problema zavisi od načina upravljanja EES-om i resursa koji su na raspolaganju u sistemu - rezultati SCOPF problema mogu da se realizuju $\mathrm{u}$ preventivnom (PSCOPF) i korektivnom (CSCOPF) modu. PSCOPF podrazumeva da sva potencijalno narušena ograničenja u sistemu sa ispadom treba otkloniti prilikom izbora upravljačkih promenljivih sistema, pri čemu u sistemu ne mora da bude podržana automatska regulacija upravljačkih veličina. CSCOPF, sa druge strane, zahteva podržanu automatsku regulaciju svih upravljačkih veličina kako bi se promena ovih veličina izvršila nakon ispada (upravljanje u zatvorenoj petlji).

Takođe, SCOPF proračun može da se primeni kako za planiranje, tako i za upravljanje mrežom u realnom vremenu. U ovom radu će biti obrađen SCOPF proračun za sistem sa jednostrukim ispadom sekcije. 


\section{MATEMATIČKI MODEL SCOPF PROBLEMA}

U ovoj glavi je data matematička formulacija SCOPF problema, potom je ukratko opisan primarno-dualni IP algoritam linearnog programiranja koji se koristi za rešavanje SCOPF problema i na kraju je prikazan algoritam za rešavanje SCOPF problema.

\subsection{Matematička formulacija SCOPF problema}

Matematička formulacija SCOPF problema je data u nastavku:

$$
\begin{aligned}
& \min f\left(x^{0}\right) \\
& G(x)=0, \\
& H(x) \geq 0,
\end{aligned}
$$

gde su :

$x^{0}$ - vektor promenljivih stanja i upravljanja za sistem u baznom stanju,

$x$ - vektor objedinjenih promenljivih stanja za sistem $\mathrm{u}$ baznom stanju, promenljivih stanja za sistem u režimu sa ispadom i promenljivih upravljanja koje su zajedničke za oba režima,

$G(x)$ - objedinjena ograničenja tokova snaga za bazno i stanje sa ispadom, i

$H(x)$ - objedinjena pogonska ograničenja za bazno i stanje sa ispadom.

\subsection{Primarno - dualni IP algoritam za rešavanje SCOPF problema}

SCOPF problem je optimizacioni problem sa ograničenjima tipa nejednakosti. U opštem slučaju, SCOPF problem je nelinearan i nekonveksan. U ovom radu je za rešavanje optimizacionog problema primenjen primarnodualni algoritam unutrašnje tačke (IP). IP algoritmi su kontinualni iterativni algoritmi. Ovi algoritmi su poznati kao algoritmi za pretragu. Pronalaženje optimuma se svodi na pronalaženje centralne putanje. Centralna putanja se dobija interpolacijom između početnog rešenja i optimuma. Za pronalaženje koraka za kretanje po centralnoj putanji koristi se Njutnova metoda. Ukoliko je početno rešenje dovoljno blizu centralne putanje, Njutnova metoda garantuje da će biti uspostavljena brza (kvadratna) konvergencija ka rešenju. Za početno rešenje se bira analitički centar oblasti, koji se dobija relativno jednostavno. Za problem obrađen u ovom radu, početno rešenje se dobija kao aritmetička sredina minimalne i maksimalne vredosti ograničenja za svaku od promenljivih veličina $i$ ograničenja tokova snaga $i / i l i$ struja za svaku sekciju i transformator. Dužina koraka kojim se ide duž centralne putanje treba da se skraćuje kako se algoritam približava optimalnom rešenju [8].

Osnovna karakteristika ove metode je tačnost aproksimacija kojom se uvode nova ograničenja u model, a najveća prepreka na koju se nailazi prilikom rešavanja jeste velika dimenzionalnost matematičkog modela, naročito kada se razmatra veliki broj mogućih ispada. Pošto radna tačka sistema koja se dobija kao rezultat proračuna mora da se nalazi u oblasti dopustivog rešenja (koja je određena pogonskim ograničenjima), javlja se i problem „sužavanja“ oblasti dopustivog rešenja što su „strožija“" uvedena ograničenja (kada dođe do ispada jednog elementa, ostatak sistema ima smanjen kapacitet za prenos energije što se u matematičkom modelu manifestuje kroz „sužavanje“ oblasti u kojoj može da se nađe dopustivo rešenje). Ovo dovodi do pojave numeričkih problema u proračunu [8]. Izvođenje matematičkog modela i primarno-dualni IP algoritam korišćeni u ovom radu dati su u [9].

\subsection{Algoritam za rešavanje SCOPF problema}

Osnovni koraci algoritma za rešavanje SCOPF problema, koji je predlaže i verifikuje ovim radom, su prikazani na slici 2.1

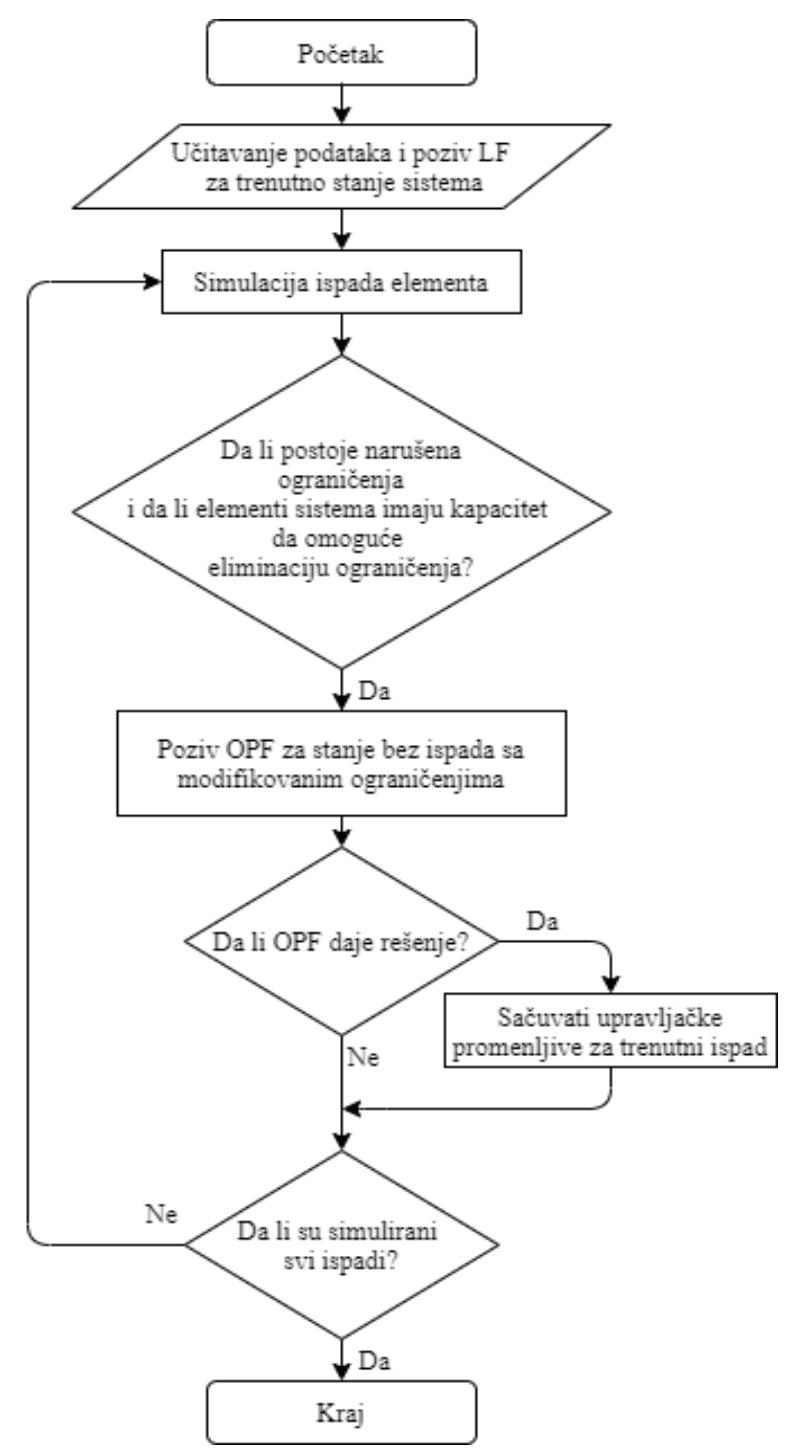

Slika 2.1. SCOPF algoritam

\section{NUMERIČKA VERIFIKACIJA SCOPF ALGORITMA}

U ovoj glavi razmatrani SCOPF algoritam je verifikovan na test sistemu od 34 čvora i 40 grana, prikazanom na slici 3.1. Od 34 čvora, u sistemu ima 6 generatorskih i 3 potrošačka. Za verifikaciju rezultata je korišćen MATPOWER softverski paket [9] koji je proširen tako što je dodata kriterijumska funkcija za minimizaciju gubitaka aktivne snage i implementiran SCOPF algoritam. 


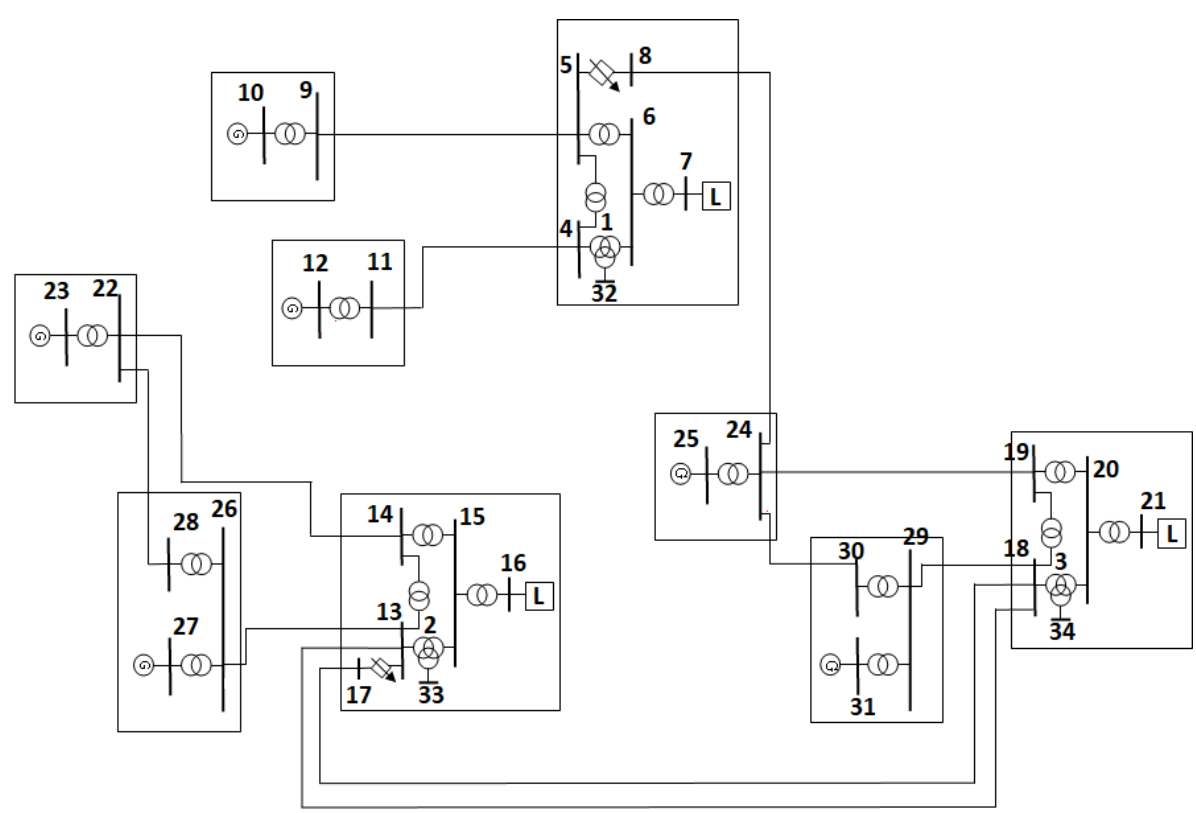

Slika 3.1. Test sistem

\subsection{Režim 1}

Vrednosti upravljačkih promenljivih za bazno stanje se nalaze u tabeli 3.1. Potrošnja je data u tabeli 3.2. Sistem nije N-1 siguran, što se vidi na osnovu prividnih snaga transformatora datih u tabeli 3.3 i potrošnje date u tabeli 3.2. Naime, za sistem u ovom režimu, u slučaju ispada tronamotajnog transformatora doći će do preopterećenja dvonamotajnog transformatora koji je u paraleli sa istim. SCOPF za eliminaciju ovih ispada ne može da ponudi rešenje. Ostali ispadi neće prouzrokovati preopterećenja u sistemu. Vrednost kriterijumske funkcije (gubici aktivne snage) za sistem u baznom stanju iznosi 3,253 MW.

Tabela 3.1. Upravljačke veličine u generatorskim čvorovima u baznom stanju za režim 1

\begin{tabular}{|c|c|c|c|}
\hline Čvor & $P[\mathrm{MW}]$ & $Q[\mathrm{MVAr}]$ & $V_{m}[\mathrm{kV}]$ \\
\hline 10 & 77 & & 16,77 \\
\hline 12 & 75 & & 17,42 \\
\hline 23 & 77 & & 16,75 \\
\hline 28 & 75 & $-51,62$ & \\
\hline 25 & 78 & & 16,75 \\
\hline 31 & 71,30 & & 16,75 \\
\hline
\end{tabular}

Tabela 3.2. Potrošnja u sistemu za režim 1

\begin{tabular}{|c|c|c|}
\hline Čvor & $P[\mathrm{MW}]$ & $Q[\mathrm{MVAr}]$ \\
\hline 7 & 150 & 62 \\
\hline 16 & 150 & 64 \\
\hline 21 & 150 & 62,60 \\
\hline
\end{tabular}

Tabela 3.3. Maksimalne prividne snage transformatora

\begin{tabular}{|c|c|}
\hline Grane & $S_{\max }[$ MVA] \\
\hline $4-6,13-15,18-20$ & 300 \\
\hline $5-6,14-15,19-20$ & 150 \\
\hline
\end{tabular}

\subsection{Režim 2}

Sistem se nalazi u režimu koji nije optimalan, ali bez narušenih pogonskih ograničenja (tabele 3.4 i 3.5). Sistem nije N-1 siguran (doći će do preopterećenja dvonamotajnih transformatora u granama $19-20,5-6$ i $14-15$ u slučaju ispada tronamotajnih transformatora $\mathrm{u}$ paralelnim granama). Izuzev ovih preopterećenja, SCOPF detektuje i ispad koji prouzrokuje preopterećenje koje može da se eliminiše. U slučaju ispada transformatora $u$ grani $4-5$, javlja se preopterećenje transformatora $u$ grani $5-6$. Tok prividne snage po grani $5-6$ nakon ispada iznosi 151,2 MVA, dok je maksimalna vrednost prividne snage za ovu granu 150 MVA (tabela 3.3). Vrednost kriterijumske funkcije sistema u baznom stanju iznosi 7,492 MW. Nakon poziva SCOPF, tok prividne snage po grani 5 - 6 u slučaju ispada iznosi 118,06 MVA, a vrednost kriterijumske funkcije 6,405 MW. Vrednosti upravljačkih promenljivih koje su dobijene kao rezultat SCOPF problema su date u tabeli 3.6.

Tabela 3.4. Upravljačke veličine u generatorskim čvorovima u baznom stanju za režim 2

\begin{tabular}{|c|c|c|c|}
\hline Čvor & $P[\mathrm{MW}]$ & $Q[\mathrm{MVAr}]$ & $V_{m}[\mathrm{kV}]$ \\
\hline 10 & 127,41 & & 17 \\
\hline 12 & 175,59 & & 17,17 \\
\hline 23 & 126,75 & & 17,18 \\
\hline 28 & 159,36 & $-24,43$ & \\
\hline 25 & 176,60 & & 17,08 \\
\hline 31 & 191,80 & & 17,27 \\
\hline
\end{tabular}

Tabela 3.5. Potrošnja u sistemu za režim 2

\begin{tabular}{|c|c|c|}
\hline Čvor & $P[\mathrm{MW}]$ & $Q[\mathrm{MVAr}]$ \\
\hline 7 & 320 & 62 \\
\hline 16 & 300 & 64 \\
\hline 21 & 330 & 62,60 \\
\hline
\end{tabular}

Tabela 3.6. Upravljačke veličine u generatorskim čvorovima za režim 2 nakon SCOPF

\begin{tabular}{|c|c|c|c|}
\hline Čvor & $P[\mathrm{MW}]$ & $Q[\mathrm{MVAr}]$ & $V_{m}[\mathrm{kV}]$ \\
\hline 10 & 83,66 & & 17,27 \\
\hline 12 & 266,01 & & 18,17 \\
\hline 23 & 98,66 & & 17,60 \\
\hline 28 & 236,17 & $-24,92$ & \\
\hline 25 & 113,14 & & 17,62 \\
\hline 31 & 158,40 & & 17,37 \\
\hline
\end{tabular}


Poboljšanje vrednosti kriterijumske funkcije za predložene vrednosti upravljačkih promenljivih u baznom stanju u odnosu na početno stanje je očekivano s obzirom da stanje sistema iz koga je simuliran ispad nije bilo optimalno.

S druge strane, vrednost kriterijumske funkcije je očekivano lošija u odnosu na optimalnu vrednost kriterijumske funkcije gubitaka aktivne snage bez uvažavanja principa sigurnosti sistema koja iznosi 6,069 MW. Vrednosti upravljačkih promenljivih za optimalno stanje bez uvažavanja sigurnosti sistema date su u tabeli 3.7.

Tabela 3.7. Upravljačke veličine za optimalno stanje bez uvažavanja principa sigurnosti

\begin{tabular}{|c|c|c|c|}
\hline Čvor & $P[\mathrm{MW}]$ & $Q[\mathrm{MVAr}]$ & $V_{m}[\mathrm{kV}]$ \\
\hline 10 & 10 & & 17,17 \\
\hline 12 & 186,03 & & 17,39 \\
\hline 23 & 109,66 & & 17,25 \\
\hline 28 & 339,99 & $-39,59$ & \\
\hline 25 & 115,89 & & 17,20 \\
\hline 31 & 194,72 & & 17,24 \\
\hline
\end{tabular}

\section{ZAKLJUČAK}

SCOPF proračun može da se primeni kako za planiranje, tako i za upravljanje mrežom u realnom vremenu.

Primenom optimizacionog algoritma kao što je SCOPF je moguće eliminisati narušena ograničenja koja nastaju nakon ispada elementa podešavanjem upravljačkih veličina u sistemu pre ispada. Za tako odabrane vrednosti upravljačkih promenljivih sistem će u baznom stanju imati nešto lošiju vrednost kriterijumske funkcije nego kada nije uvažena sigurnost sistema, što je relativno mala cena koja treba da se plati kada se ide na stranu sigurnosti. Ova tvrdnja je upravo dokazana na primeru test sistema $\mathrm{u}$ režimu 2, ako se uporede vrednosti kriterijumskih funkcija za bazno stanje sa i bez uvažavanja principa sigurnosti.

SCOPF algoritam implementiran u ovom radu odlikuje jednostavan pristup ažuriranju ograničenja. Međutim, bitno je napomenuti da je zbog usvojenog jednostavnog pristupa izgubljeno na preciznosti algoritma. Dodatno, problem pronalaženja rešenja se usložnjava ukoliko se razmatra veći broj ispada. Konačno, vreme potrebno za izvršavanje proračuna zavisi od odabrane metode za detekciju kritičnih ispada. U ovom radu se pozivaju AC tokovi snaga za proračun tokova snaga nakon ispada $u$ cilju detekcije narušenih ograničenja u sistemu. Bitno je napomenuti da ovaj pristup oduzima dosta vremena čak i za mali test sistem koji je korišćen u ovom radu pa je neophodno da se za veći sistem koriste druge metode koje ubrzavaju proračun, kao npr. pomenuta metoda PTDF faktora.

\section{LITERATURA}

[1] J. Carpentier, „Contribution to the Economic Dispatch Problem", Bulletin de la Societe Francoise des Electriciens, 1962.

[2] J. Zhu, „Optimization of Power System Operation“, Hoboken, New Jersey, United States, John Wiley \& Sons, Inc., 2015.

[3] H. W. Dommel, W. F. Tinney, „Optimal Power Flow Solutions “, IEEE Transactions on Power Apparatus and System, PAS 87, Issue 10, Oct. 1968.

[4] Milan S. Ćalović, Andrija T. Sarić, Predrag Č. Stefanov, „Eksploatacija elektroenergetskih sistema u uslovima slobodnog tržišta “, Čačak, Republika Srbija, Tehnički fakultet Čačak, 2005.

[5] O. Alsac, B. Stott, „Optimal Load Flow with SteadyState Security “, IEEE Transactions on Power Apparatus and Systems, PAS 93, Issue 3, May 1974.

[6] N. Hadjsaid, M. Benahmed, J. Fandino, J.C. Sabonnadiere, G. Nerin, „Fast contingency screening for voltage-reactive considerations in security analysis “, IEEE Transactions on Power Systems, Vol. 8, Issue 1, Feb. 1993.

[7] G.C. Ejebe, H.P. Van Meeteren, B.F. Wollenberg, „Fast Contingency Screening and Evaluation for Voltage Security Analysis “, IEEE Transactions on Power Systems, Vol. 3, Issue 4, Nov. 1988.

[8] Yinyu Ye, „Introduction and Preliminiaries. Interior Point Algorithms: Theory and Analysis “, New York, United States, John Wiley \& Sons, Inc., 1997.

[9] Ray D. Zimmerman, Carlos E. Murillo-Sánchez, „MATPOWER 6.0 Users's Manual “, Power Systems Engineering Reseach Center (PSERC), New York, United States, 2016.

\section{Kratka biografija:}

Ivana Mirković rođena je u Loznici 1993. godine. Osnovne studije završila je na Fakultetu tehničkih nauka iz oblasti Elektrotehnike i računarstva - Elektroenergetski sistemi 2017. god. i 2017. god. upisala master studije na istom fakultetu.

Savo Đukić rođen je u Novom Sadu 1983. godine. Doktorsku disertaciju odbranio je 2014. godine na Fakultetu tehničkih nauka iz oblasti Elektroenergetski sistemi. 